\title{
A proposal of using fuzzy system to integrate scores of Health and Environment: a case study at Brazil
}

\author{
Daniel Canavese ${ }^{1}$, Neli Regina Siqueira Ortega ${ }^{2}$ \\ ${ }^{1}$ Federal University of Parana, Coast Campus, Public Health Discipline, Matinhos, Brazil \\ ${ }^{2}$ University of Sao Paulo, School of Medicine, Medical Informatics, Sao Paulo, Brazil
}

\begin{abstract}
The growth of cities, climate change, biomes degradation, disease and social issues influence the views of life quality and health of populations. The characteristics of health and environment are usually measured with different and disconnected indicators. However, the importance of working with those two aspects in a joined way is every time larger. In this paper it is presented a fuzzy rule-based system to aggregate measures of population health and environment in order to produce an integrate index. This fuzzy index was applied to all states of Brazil and the results were in agreement with the expected.
\end{abstract}

Keywords: Fuzzy Logic; Ecosystem approach; Environmental health assessment

\section{Introduction}

The growth of cities, climate change, biomes degradation, disease and social issues influence the views of life quality and health of populations. The recognition of these aspects is the starting point of this issue. There are different proposals of studies aiming to contribute in understanding the interfaces among health and environment. Recently some of them are integrating indicators while considering uncertainty and possibly enhancement of knowledge using Fuzzy Logic.

Numerous publications dealt with the topic. In 1974 the publication "Environmental, health, and human ecologic considerations in Economic Development projects", World Bank, listed out a number of considerations, criteria and standards for this issue. This was one of the first initiatives after the Unite Nations Conference on the Human Environment held in 1972 in Stockholm, Sweden. Centered on a primarily economic perspective the document became a landmark to establish measures for environmental monitoring.

It is not unusual to measure health and environmental characteristics using different kind of indicators. That happens because there is a necessity to characterize, to analyze and to monitor the population and their ecosystems condition. Early studies in public health already use a synthesis value. Many of them combine information like mortality. To describe environmental impacts it is measured situations such as water pollution, deforestation, climate change, trash disposal or occurrence of species extinction. This is important for subsidizing different situations in areas like governance and management.

Although uncertainty and vagueness are present in many health and environment measure conditions, it is usually not considered in the process of production of information and interpretation of the population indicators. As mentioned, environment and health should be analyzed as an integrated panorama and considering uncertainty and complexity.

In this sense new methodologies are required today. The ecosystem approach presents contributions to the theme. Yet it is not suggested the use of new techniques but rather the redirection of methodologies. For this reason attributes such as transdisciplinarity and integrated analysis are regarded as essential. Besides these aspects, uncertainty, commonly discarded in the process of production of information and interpretation of reality, is an important element to be considered.

In his article Silvert presents an applicability of fuzzy logic to assessment the environmental impact [1]. Also in this area Chen et al. reported the problem of dispersion of water pollutants during the oil extraction [2]. The authors proposed a hybrid model combining fuzzy logic and stochastic approach to predict and assess different patterns of pollution in the marine environment. This model could contribute to implementation of protective meas- 
ures of disease and harm reduction. Shan et al. developed a study based on fuzzy theory to evaluate township ecosystem health [3]. In the health areas the interest for soft computing techniques has been growing exponentially along the time. However, there are few works in epidemiology and collective health. Several applications of fuzzy logic to epidemic control strategies is presented by Massad and collaborators in $[4,5]$. In another work Nascimento and Ortega studied a linguistic model for estimating the risk of neonatal death [6]. Gradually there is a recruitment of researches that consider integrated measures when talking about health and environment. Such challenge happens in order to broaden the understanding of relationships between ecological systems and human societies.

In this paper it is presented a fuzzy rulebased model to aggregate measures of health and environment in order to produce an integrate index. This fuzzy index was applied to assessment all states of Brazil.

\section{Modeling Procedures}

The development of an integrated fuzzy rule-based model for ecosystem management has involved three phases. That task involved the participation of public health experts.

The first phase refers to the selection of health and environment information. The researchers had chosen those important variables which were usually available on health and environment databases sites of Brazilian government, such as Health Ministry, Cities Ministry and Environmental Ministry. Considering this it has been arranged a composition as shown in table 1 . The areas dimensions were composed by these main indicators references.

To contextualize health there were information related to mortality in infants between the age of 1 year and 5 years. It was considered mortality for all causes and specific causes like respiratory and diarrhea diseases. Information about the coverage of sanitation services like water quality, garbage treatment and green areas were selected to discuss environmental conditions.
Table 1

Area dimensions and indicators reference for the domains of the fuzzy ruled-based model

Area dimension :Health

Child mortality Rate

Child mortality due to infectious and parasitic diseases

Under-5 proportional mortality due to diarrhoea

Under-5 proportional mortality due to respiratory disease

Area dimension: Environment

Proportion of population covered by garbage collection

Proportion of population covered by sewerage

Proportion of population covered by water supply

network

The data of all Brazilian states were available for public consulting at Health Ministry internet site [7]. This information refers to the Brazilian population during the year of 2007.

The second phase involved the elaboration of a fuzzy linguistic model. It was elaborated a Mamdani model with two domains: health and environment. The researchers decided to summarize the information inside health and environmental area. For this first model prototype it was implemented the sum of all indicators in the respective area. So, each composing indicator had the value divided by the medium value of its category. Then a sum was executed within the area composing the domain of input variables.

Still in this phase it has been consolidated the fuzzy inference system which aggregates the if-then rules. The Minimum of Mamdani was the inference method for the linguistic model.

After fuzzification, in an opposite way, it was necessary to present fuzzy information in a crisp format. To conduct the defuzzification the Center of the Area method has been chosen. The model should then originate a synthesized measure of environmental health.

The last phase refers to some adjusts that has been executed during the pilot tests. It has to be considered that, particularly in environmental health management, the validation of the systems is determined by their value to po- 
tential users and their application. There is no gold standard for the majority of those phenomena, among other reasons. Finally, in this phase the fuzzy model was applied for all Brazilian states.

\section{Results}

The rule-based fuzzy model developed has two input linguistic variables: the synthetic health score and the synthetic environment score. Each input linguistic variable were classified in four linguistic terms: optimal, good, regular and critical, resulting in 16 rules in the system. It synthesizes information on these domains and generates an index called Index of Environmental Health (IEH). The IEH also has a gradation in the same linguistic terms.

Using defuzzification process it was obtained a numeric valor for IEH ranging from 0 (worst situation) till 10 (best situation). Figures 1 to 3 show the membership functions of the linguistic variables for the synthetic health score, the synthetic environment score, and the Index of Environmental Health, respectively.

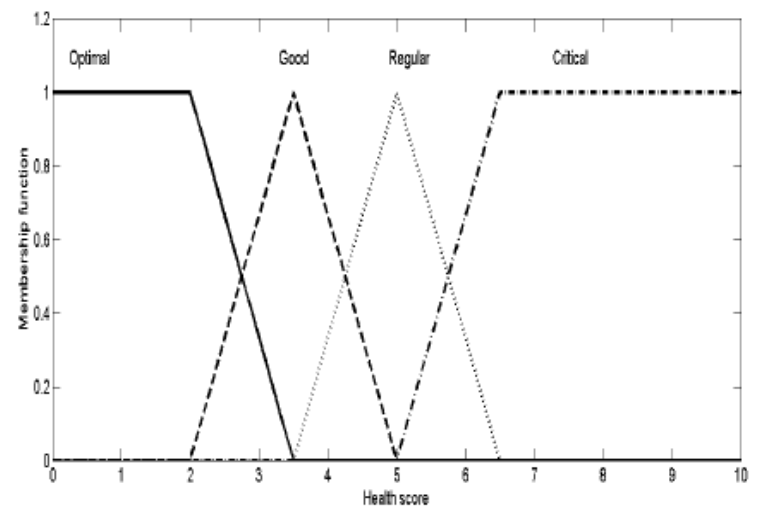

Fig. 1: Membership functions of the synthetic health score.

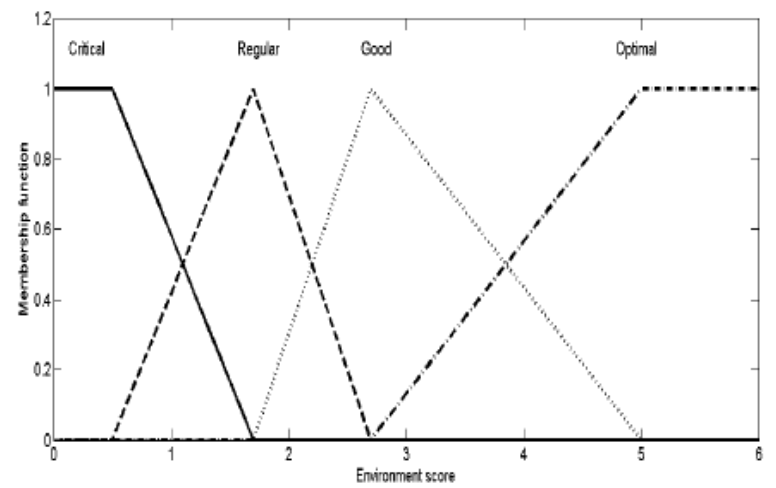

Fig. 2: Membership functions of the synthetic environment score.

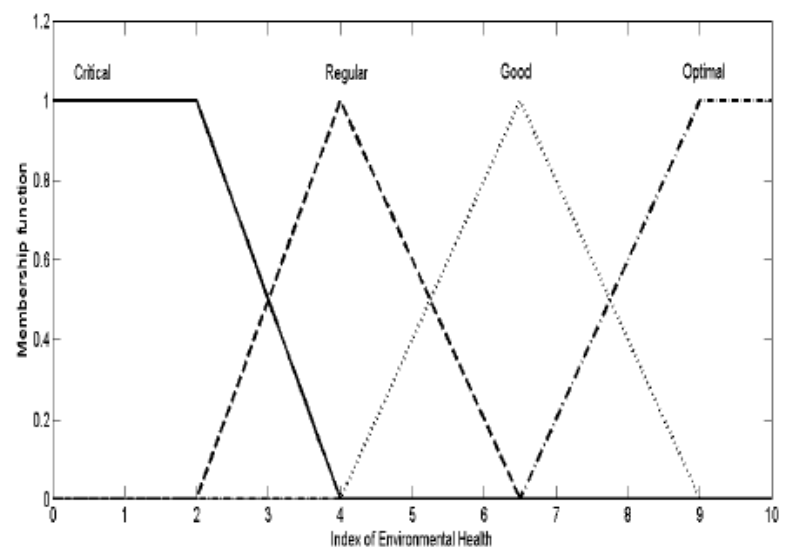

Fig. 3: Membership functions of the Index of Environmental Health.

In order to evaluate the performance of a fuzzy model it was applied to estimate the IEH of all Brazilian states. Table 2 presents the health and environment scores and the fuzzy index (IEH) for all Brazilian States. 
Table 2

Values of environmental and health scores of all Brazilian States and the fuzzy Index of Environmental Health (IEH)

\begin{tabular}{|c|c|c|c|}
\hline State & $\begin{array}{l}\text { Envi- } \\
\text { ronmen- } \\
\text { tal } \\
\text { Score }\end{array}$ & $\begin{array}{l}\text { Health } \\
\text { Score }\end{array}$ & IEH \\
\hline Rondônia $^{1}$ & 1,85 & 5,38 & 1,85 \\
\hline Acre $^{1}$ & 2,45 & 6,43 & 3,57 \\
\hline Amazonas ${ }^{1}$ & 2,94 & 6,83 & 4,00 \\
\hline Roraima $^{1}$ & 3,52 & 5,33 & 4,00 \\
\hline Pará $^{1}$ & 2,57 & 9,51 & 3,97 \\
\hline Amapá1 & 2,98 & 2,61 & 6,50 \\
\hline Tocantins $^{1}$ & 2,42 & 5,00 & 3,47 \\
\hline Maranhão $^{2}$ & 2,43 & 9,75 & 3,50 \\
\hline Piauí $^{2}$ & 2,51 & 5,73 & 3,72 \\
\hline Ceará $^{2}$ & 2,70 & 8,31 & 4,00 \\
\hline Rio Grande do Norte ${ }^{2}$ & 3,08 & 5,99 & 4,00 \\
\hline Paraíba $^{2}$ & 2,91 & 5,95 & 4,00 \\
\hline Pernambuco $^{2}$ & 2,77 & 11,23 & 4,00 \\
\hline Alagoas $^{2}$ & 2,33 & 10,91 & 3,17 \\
\hline Sergipe $^{2}$ & 3,37 & 6,37 & 4,00 \\
\hline Bahia $^{2}$ & 2,85 & 9,74 & 4,00 \\
\hline Minas Gerais ${ }^{3}$ & 3,54 & 5,64 & 4,00 \\
\hline Espírito Santo $^{3}$ & 3,46 & 2,54 & 6,56 \\
\hline Rio de Janeiro ${ }^{3}$ & 3,88 & 5,65 & 4,00 \\
\hline São Paulo ${ }^{3}$ & 4,06 & 8,74 & 4,00 \\
\hline Paraná $^{4}$ & 3,43 & 3,80 & 6,12 \\
\hline Santa Catarina ${ }^{4}$ & 3,61 & 2,36 & 6,90 \\
\hline Rio Grande do $\mathrm{Sul}^{4}$ & 3,62 & 3,15 & 6,50 \\
\hline Mato Grosso do Sul & 2,63 & 6,51 & 4,00 \\
\hline Mato Grosso 5 & 2,24 & 4,96 & 2,86 \\
\hline Goiás $^{5}$ & 2,91 & 3,69 & 6,50 \\
\hline Distrito Federal $^{5}$ & 4,05 & 2,43 & 8,94 \\
\hline
\end{tabular}

Regions of Brazil: 1. North, 2. Northeast, 3. Southeast, 4. South and 5. Midwest

Grouping the Brazilian states in your respective areas allow as to observe how the model discriminates the situation of health and environment for the regions in Brazil (Figure 4).

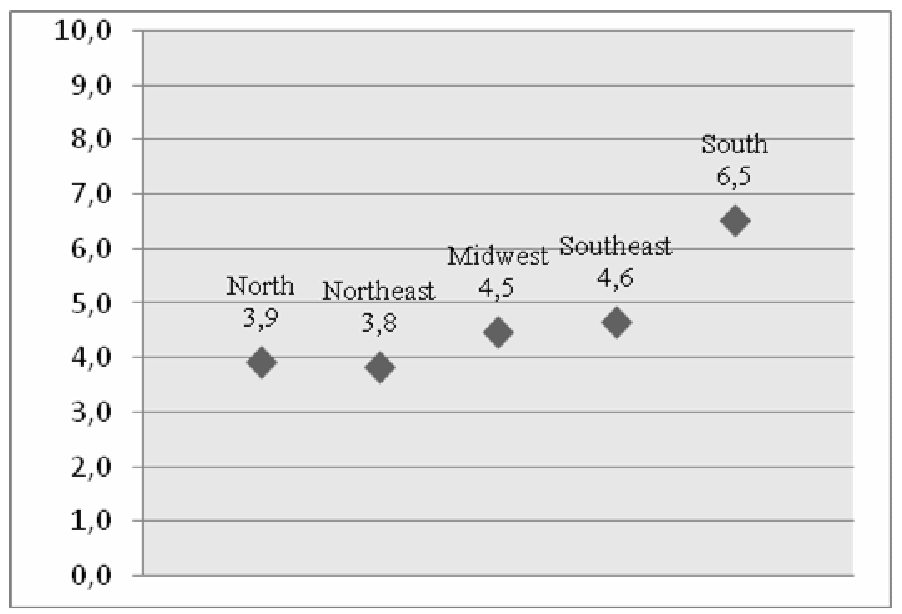

Fig. 4: Graphic of Index of Environmental Health obtained from fuzzy rule-based models to Brazilian regions

\section{Discussion}

The fuzzy ruled-based model presented the property of classification different conditions. In addition to that it generates integrated measures from environmental health in quantitative ways. It can be very useful to establish the state of the art about this theme.

The IEH has show also the possibility of interaction with other indicators enabling the formulation of scenarios and foresights. This is especially interesting because it enables the discussion of environmental health in perspectives like monitoring. Also it evocates integrated analysis of the situation and helps the planning of actions. It can be used as an important instrument for public policies and other works.

The highest IEH value was obtained at South and Southeast regions indicating evidences of better conditions. The IHE corroborates the mapping of regional development characteristics in Brazil. The measurement responsiveness was suitable while revealing disparities among regions. The north region had the lowest IEH scores and evocates the actual necessity of improvements in sanitation and health procedures. Both situations are part of reality at Brazilian territory nowadays. Future 
studies of this model will improve it and test among Brazilian states and cities.

\section{Conclusions}

Elaborating measurements of environmental health conditions using the Fuzzy Logic model has shown important perspectives. The fuzzy linguistic model demonstrated to be robust in the proposal of generating integrated measures of health and environment, presenting results in agreement with the Brazilian reality.

\section{Acknowledgement}

This work was financially supported by CNPq and HCFMUSP/LIM01.

\section{References}

[1] W. Silvert, Ecological impact classification with fuzzy sets, Ecological Modelling, 96:1-10, 1997.

[2] Z. Chen, L. Zhao, K. Lee, Environmental risk assessment of offshore produced water discharges using a hybrid fuzzy-stochastic modeling approach, Environmental Modelling \& Software, 25:782-92, 2010.

[3] S. Shan, L. Zhang, X. Wang, B. Chen, Township ecosystem health assessment based on fuzzy synthesis evaluation method: a case study of Tongzhou District, Beijing, China. Front. Earth Sci. China, 3(3): 312--319, 2009. [4] E. Massad, M.N. Burattini, N.R.S. Ortega, Fuzzy logic and measles vaccination: designing a control strategy, International Journal of Epidemiology, 28:550--7,1999.

[5] E. Massad, N.R.S. Ortega, L.C. Barros, C.J. Struchiner, Fuzzy Logic in Action: applications in Epidemiology and beyond, Heidelberg: Springer, 2008.

[6] L.F.C. Nascimento, N.R.S. Ortega, Linguistic model for estimating the risk of neonatal death, Public Health, 36(6):686--92, 2002.

[7] Brazilian Health Ministry internet site, www.datasus.gov.br, last access in December, 2010. 